\title{
Fluorous Mixture Synthesis of Four Stereoisomers of the C21- C40 Fragment of Tetrafibricin
}

\author{
Kai Zhang and Dennis P. Curran \\ Department of Chemistry, University of Pittsburgh, Pittsburgh, PA 15260, USA Fax \\ $+1(412) 6249861$ \\ Dennis P. Curran: curran@pitt.edu
}

\begin{abstract}
Four stereoisomers of the $\mathrm{C} 21-\mathrm{C} 40$ fragment are synthesized in a single exercise with the aid of fluorous tagging to encode configurations at $\mathrm{C} 37$ and C33. After demixing and detagging, the isomers were found to have substantially identical ${ }^{1} \mathrm{H}$ NMR spectra. However, there were some small but reliable differences in their ${ }^{13} \mathrm{C}$ NMR spectra.
\end{abstract}

\section{Keywords}

tetrafibricin; fibrinogen; fluorous mixture synthesis; quasiisomers; Kocienski-Julia reaction

In 1993, Kamiyama and co-workers described the isolation and two-dimensional structure (constitution) of the interesting natural product tetrafibricin (1, Figure 1). ${ }^{1}$ The compound is an $\omega$-amino acid whose terminal groups are separated by 39 carbon atoms. Adding the carboxylate, the total length of the carbon backbone is 40 atoms. The chain features seven $E$ alkenes, ten hydroxy groups, a ketone, and a lone methyl group.

Tetrafibricin strongly inhibited the binding of fibrinogen to its glycoprotein receptor $\left(\mathrm{IC}_{50}=\right.$ $46 \mathrm{nM}$ ). It also inhibited ADP-, collagen-, and thrombin-induced aggregation of human platelets. ${ }^{1}$ Accordingly, it has potential as a therapeutic agent for arterial thrombotic diseases.

Assignment of the three-dimensional structure (configuration) of tetrafibricin is a problem because the stereocenters or groups of stereocenters are insulated from each other by 2-3 chain carbon atoms. Kishi and co-workers addressed the problem without using either classical derivatization or degradation by comparing NMR data of the natural product and its ketone reduction products collected in both chiral and achiral solvents to values in a database built from spectra of suitable model compounds. ${ }^{2}$

It would be valuable to confirm the structure of tetrafibricin by total synthesis. Syntheses of various fragments and assorted couplings have been described by Cossy ${ }^{3 a}$ and Roush ${ }^{3 b}$ as well as by our group. ${ }^{3 \mathrm{c}, \mathrm{d}} \mathrm{We}$ are also interested in making stereoisomers of tetrafibricin both to flesh out SAR and to learn whether and how the isomers can be differentiated. Towards

Correspondence to: Dennis P. Curran, curran@pitt . edu.

Dedicated to Prof. Gerry Pattenden in celebration of his $70^{\text {th }}$ birthday

Supporting Information for this article is available online at http://www.thieme-connect.com/ejournals/toc/synlett. The file contains full experimental details and compound characterizations along with copies of NMR spectra of quasiisomers $\mathbf{2 1}$ and diastereomers $\mathbf{2}$ and a comparison table of ${ }^{13} \mathrm{C}$ NMR chemical shifts of 2 . 
these ends, we describe herein the synthesis of four stereoisomers of a large bottom fragment of tetrafibricin. We use the technique of fluorous mixture synthesis ${ }^{4}$ to make all four isomers together in a single synthetic sequence.

The retrosynthetic analysis of tetrafibricin breaks the molecule at the $\mathrm{C} 20-\mathrm{C} 21$ alkene into large top and bottom fragments of comparable size and complexity. Further analysis of the bottom fragment 2 is shown in Scheme 1. This has two stereocenters (C33 and C37) that are isolated from others by three atoms along with a group of four stereocenters (C23-C29) on alternating carbon atoms.

Accordingly, coupling of $\mathbf{3}, \mathbf{4}$, and 5 by Kocienski-Julia reactions ${ }^{5}$ should provide the bottom fragment 2 with flexible access to various isomers. To make the set of four possible diastereomers that these three isomer groups engender, we decided to fix the absolute configuration of the large fragment $\mathbf{5}$ while making small fragments $\mathbf{3}$ and $\mathbf{4}$ as quasiisomer mixtures ${ }^{4 \mathrm{e}}$ with component configurations encoded by fluorous tags (mixture samples are denoted by the prefix ' $M$ '). This fluorous mixture synthesis was patterned after a single isomer synthesis by Dr. V. Gudipati. ${ }^{3 c}$

The synthesis of quasiracemate M-3 is summarized in Scheme 2. Epoxide $(R)-\mathbf{6}$ was prepared by a Jacobsen hydrolytic kinetic resolution (HKR), ${ }^{6}$ then opened with lithiodithiane to give $(R)-7$ in $70 \%$ yield. ${ }^{7}$ Likewise, $(S)-7$ was prepared from $(S)-6$ (not shown). The configurations at $\mathrm{C} 37$ were encoded by silylation with fluorous silyl tri-flates; $(R)-7$ was reacted with $8 \mathbf{a}$ bearing a $\mathrm{C}_{4} \mathrm{~F}_{9}$ substituent while $(S)-7$ was reacted with $\mathbf{8 b}$ bearing a $\mathrm{C}_{3} \mathrm{~F}_{7}$ substituent. ${ }^{8}$ The resulting quasienantiomers $(R)-\mathbf{9 a} /(S)-9 \mathbf{b}(88 \%$ and $90 \%$ yields) were mixed in equal amounts to make a quasiracemate M-9a,b, then the dithiane was carefully hydrolyzed with mercuric perchlorate to provide M-10a,b $(90 \%){ }^{9}$

Reduction of M-10a,b with DIBAL-H (73\%), Mitsunobu reaction ${ }^{10}$ of the resulting alcohol with 1-phenyl-1 $H$-tetra-zole-5-thiol (PTSH, 92\%), and finally mCPBA oxidation (80\%) provided the target sulfone component M-3a,b for first Kocienski-Julia coupling.

The synthesis of the aldehyde component for first coupling is shown in Scheme 3. Coupling of alcohol $(S)$-11 with PTSH as above (79\%) followed by hydrolysis $(93 \%)$ and selective silylation of the primary alcohol with TBSCl $(91 \%)$ provided $(S)-\mathbf{1 2}$. Likewise, $(R)-\mathbf{1 2}$ was made by the same sequence of reactions starting from $(R)-11 .{ }^{8}$

The $S$-enantiomer was tagged with silyl triflate bearing a $\mathrm{C}_{6} \mathrm{~F}_{13}$ group to give $(S)-\mathbf{1 3 c}$. In turn quasienantiomer $(R)$-13a with a $\mathrm{C}_{4} \mathrm{~F}_{9}$ group was made from $(R)-\mathbf{1 2}$ and 8a. Both silylations occurred in $90 \%$ yield.

These quasienantiomers were mixed in equal portions to give quasiracemate M-13a,c. The TBS group was selectively removed by careful hydrolysis with $\mathrm{HCl}$ in methanol $(60 \%)$, and the resulting alcohol was oxidized with Dess-Martin reagent to give M-4a,c (81\%, Scheme 3). ${ }^{11}$

The synthesis of the single enantiomer of the C21-C30 fragment 5 is summarized in Scheme 4. Epoxide $(S, S)$-14 was prepared by Jacobsen HKR, ${ }^{6}$ then opened with lithiodithiane $(83 \%) .{ }^{7}$ Hydrolysis of the acetal followed by protection of the resulting triol with TBSOTf gave trissilyl ether $\mathbf{1 5}$ ( $88 \%$ over two steps).

Deprotonation of 15 with $t$-BuLi and reaction of the derived dithiane anion with epoxide $(R)$-16 provided $\mathbf{1 7}$ in $90 \%$ yield. Dithiane hydrolysis (84\%) followed by directed reduction provided a 1,3-anti-diol trissilyl ether ${ }^{12}$ that was further protected with TBSOTf to provide pentakissilyl ether 18 (73\% for two steps). Selective desilylation of the primary TBS ether 
with HF.pyridine ${ }^{13}$ occurred in $49 \%$ yield, then Dess-Martin oxidation11 provided aldehyde $\mathbf{5}$ as a single isomer.

The fragment couplings and completion of the synthesis of the four isomers of $\mathbf{2}$ were all conducted in fluorous mixture mode, as summarized in Scheme 5. Kocienski-Julia coupling of quasiracemates M-3a,b and M-4a,c with KHMDS in DME provided a mixture of four quasiisomers M-19 with an $E / Z$ selectivity of about 9:1. Furthermore, we discovered that we could separate the minor $Z$-isomers without demixing any of the quasiisomers by preparative HPLC on a Whelk-O1 column. Thus, even though the crude Kocienski-Julia product contained eight true isomers $(E / Z)$ and quasiisomers combined, the chromatogram exhibited only two peaks; a major one consisting of the four $E$-quasiisomers (M-19) and a minor one of the four Z-quasiisomers.

Oxidation of the purified M-19 provided sulfone M-20, ${ }^{14}$ which was them coupled with 5 as above to provide alkene M-21. Again this was a mixture of four quasiisomers, each which was present as about a 9:1 mixture of $E / Z$ isomers. Yet again preparative HPLC separated the four minor $Z$-quasiisomers without demixing the major $E$-isomers.

The mixture of four $E, E$-quasiisomers M-21 was readily demixed into its individual components by preparative HPLC over a Fluoroflash ${ }^{15}$ column. A representative HPLC trace of a preparative run is shown in Figure S1 of the Supporting Information, and a summary of the product structures with configurations and tags is shown in Scheme 5. Final detagging to give the true isomers of $\mathbf{2}$ proved difficult because of the polarity of the product. However, desilylation with TASF in $\mathrm{DMF}^{4 \mathrm{~b}}$ followed by solvent removal and direct purification provided each of the four individual isomers in pure form in about $75 \%$ yield.

An important goal of this work was to learn whether the four diastereomers of $\mathbf{2}$ could be differentiated from each other by NMR spectroscopy. Copies of the ${ }^{1} \mathrm{H} N M R$ and ${ }^{13} \mathrm{C}$ NMR spectra of the four pure isomers of $\mathbf{2}$ are provided in the Supporting Information. The four ${ }^{1} \mathrm{H}$ NMR spectra in $\mathrm{CDCl}_{3}$ at $700 \mathrm{MHz}$ were substantially identical. In other words, none of the four isomers of $\mathbf{2}$ could be differentiated from any other by this means.

The four ${ }^{13} \mathrm{C}$ NMR spectra $\left(\mathrm{CDCl}_{3}\right.$ at $\left.175 \mathrm{MHz}\right)$ were very similar, but not identical. In particular, the 33,37-anti isomers $(R, R$ and $S, S)$ could be differentiated from the syn isomers $(R, S$ and $S, R)$ by the chemical shift of alkene carbon 35, which was below $\delta=128.90 \mathrm{ppm}$ for the anti isomers and above $\delta=128.90 \mathrm{ppm}$ for the syn isomers. Chemical shift differences for C 35 of the syn/anti isomers range from $0.12-0.23 \mathrm{ppm}$. Though small, these differences are probably reliable. Oishi and co-workers have recently identified a similar effect in related substructures of amphidiniol 3, which led them to revise the structure of this natural product. ${ }^{16}$

Differentiating the pairs of C33/C37 syn and anti isomers from each other $(R, R$ from $S, S$ and $R, S$ from $S, R$ ) is more difficult. However, we suggest that this can be achieved by comparing the chemical shifts of C35 (again) and C31. Here, the differences are less, 0.04-0.07 ppm, but the confidence level is increased since there are two values to compare. There are other small differences in the ${ }^{13} \mathrm{C}$ NMR spectra, that are tabulated in the Supporting Information along with all possible isomer subtractions to facilitate comparison.

In summary, we have made four stereoisomers of a large bottom fragment of tetrafibricin and compared them to each other by ${ }^{1} \mathrm{H}$ NMR and ${ }^{13} \mathrm{C}$ NMR spectroscopy. Although the stereoclusters are separated from each other by only three carbon atoms, the ${ }^{1} \mathrm{H}$ NMR spectra of the isomers are substantially identical. The ${ }^{13} \mathrm{C}$ NMR spectra are very similar, but 
not completely identical. We have learned from comparison of the spectra which resonances are diagnostic for differentiating the isomers.

\section{Supplementary Material}

Refer to Web version on PubMed Central for supplementary material.

\section{Acknowledgments}

We thank the National Institutes of Health, National Institute of General Medical Sciences, for funding this work.

\section{References and Notes}

1. (a) Kamiyama T, Itezono Y, Umino T, Satoh T, Nakayama N, Yokose K. J Antibiot 1993;46:1047. [PubMed: 8360098] (b) Kamiyama T, Umino T, Fujisaki N, Fujimori K, Satoh T, Yamashita Y, Ohshima S, Watanabe J, Yokose K. J Antibiot 1993;46:1039. [PubMed: 8360097]

2. Kobayashi Y, Czechtizky W, Kishi Y. Org Lett 2003;5:93. [PubMed: 12509899]

3. (a) BouzBouz S, Cossy J. Org Lett 2004;6:3469. [PubMed: 15387525] (b) Lira R, Roush WR. Org Lett 2007;9:533. [PubMed: 17249805] (c) Gudipati, V. PhD Thesis. University of Pittsburgh; USA: 2008. http://etd.library.pitt.edu/ETD/available/etd-04212008-115104/ (d) Gudipati V, Bajpai R, Curran DP. Collect Czech Chem Commun 2009;74:774.

4. (a) Luo ZY, Zhang QS, Oderaotoshi Y, Curran DP. Science 2001;291:1766. [PubMed: 11230688] (b) Yang F, Newsome JJ, Curran DP. J Am Chem Soc 2006;128:14200. [PubMed: 17061905] (c) Jung WH, Guyenne S, Riesco-Fagundo C, Mancuso J, Nakamura S, Curran DP. Angew Chem Int Ed 2008;47:1130. (d) Curran DP, Sui B. J Am Chem Soc 2009;131:5411. [PubMed: 19323551] (e) Zhang QS, Curran DP. Chem Eur J 2005;11:4866.

5. Blakemore PR. J Chem Soc, Perkin Trans 1 2002:2563.

6. Schaus SE, Brandes BD, Larrow JF, Tokunaga M, Hansen KB, Gould AE, Furrow ME, Jacobson EN. J Am Chem Soc 2002;124:1307. [PubMed: 11841300]

7. Gaunt MJ, Hook DF, Tanner HR, Ley SV. Org Lett 2003;5:4815. [PubMed: 14653681]

8. Zhang W, Luo Z, Chen CHT, Curran DP. J Am Chem Soc 2002;124:10443. [PubMed: 12197746]

9. Smith AB III, Pitram SM, Fuertes MJ. Org Lett 2003;5:2751. [PubMed: 12868906]

10. Mitsunobu O. Synthesis 1981:1.

11. Dess DB, Martin JC. J Org Chem 1983;48:4155.

12. Blakemore PR, Browder CC, Hong J, Lincoln CM, Nagornyy PA, Robarge LA, Wardrop DJ, White JD. J Org Chem 2005;70:5449. [PubMed: 15989326]

13. Jung WH, Harrison C, Shin Y, Fournier JH, Balachandran R, Raccor BS, Sikorski RP, Vogt A, Curran DP, Day BW. J Med Chem 2007;50:2951. [PubMed: 17542572]

14. Paquette LA, Chang S. Org Lett 2005;7:3111. [PubMed: 15987218]

15. (a) The column is available from Fluorous Technologies, Inc. (b) D.P.C. owns an equity interest in this company.

16. Oishi T, Kanemoto M, Swasono R, Matsumori N, Murata M. Org Lett 2008;10:5203. [PubMed: 18959425] 


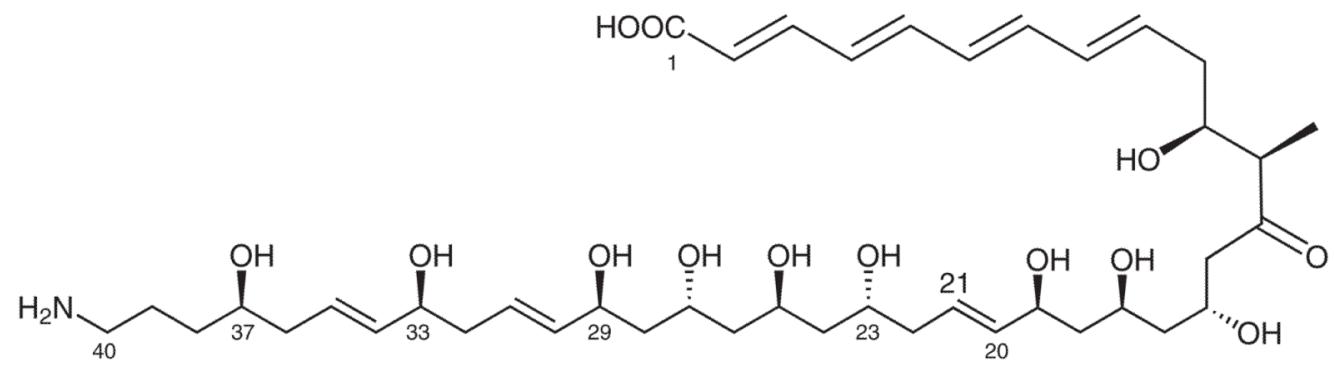

Figure 1.

Proposed structure of tetrafibricin (1) 
<smiles>C[R16]OC[C@@H](O)C[C@@H](O)C[C@@H](O)C[C@@H](O)/C=C/C[C@@H](O)/C=C/C[C@@H](O)CCC(O)O</smiles>

target bottom fragment 2

- single epimer at C29-C33

- both epimers at C33 and C37

- $\mathrm{OH}$ in place of $\mathrm{NH}_{2}$ at $\mathrm{C} 40$ simplifies

- PMB on $\mathrm{O} 21$ for selective protection and UV activity (PMB is $p$-methoxybenzyl)<smiles>[O-][Te]OCCC[C@@H](O)CCSc1nnnn1-c1ccccc1</smiles>

M-3, C35-C40 mixture of two quasiisomers<smiles>O=C[C@H](CCSc1nnnn1-c1ccccc1)C(F)(F)F</smiles>

$\mathrm{M}-4, \mathrm{C} 31-\mathrm{C} 34$ mixture of two quasiisomers

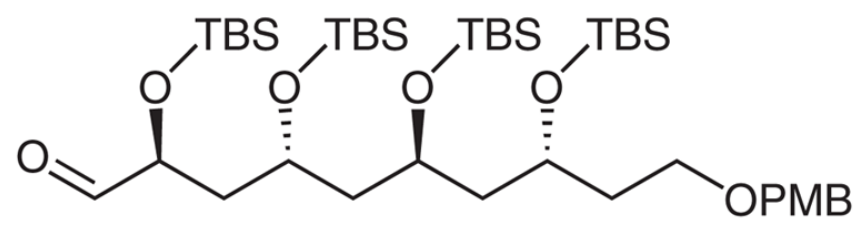

5, C21-C30 single isomer

FTIPS groups are $\mathrm{Si}\left(i-\mathrm{Pr}_{2}\right) \mathrm{CH}_{2} \mathrm{CH}_{2} \mathrm{Rf}$ where $\mathrm{Rf}$ is $\mathrm{C}_{3} \mathrm{~F}_{7}, \mathrm{C}_{4} \mathrm{~F}_{9}$ or $\mathrm{C}_{6} \mathrm{~F}_{13}$ the quasiisomer coding is shown in the synthesis schemes

Scheme 1.

Retrosynthetic analysis of bottom fragment $\mathbf{2}$ 


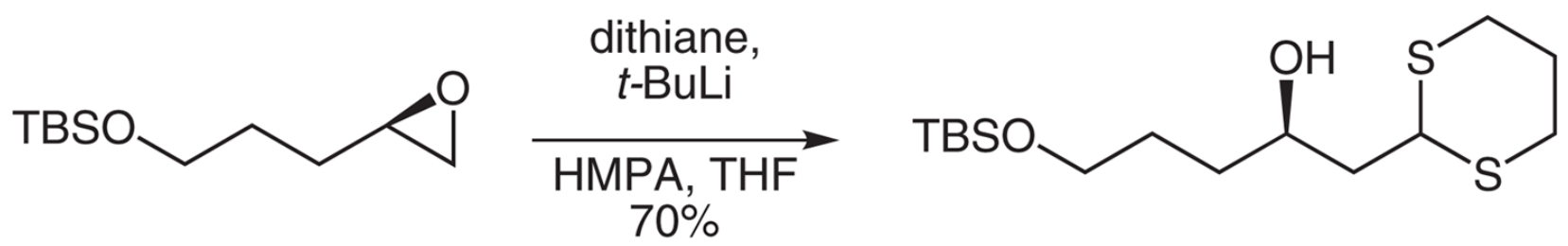

(R)-6

(R)-7

1) react $R+\mathbf{8 a}, 88 \%$
2) react $S+\mathbf{8 b}, 90 \%$

3) $\operatorname{mix}$

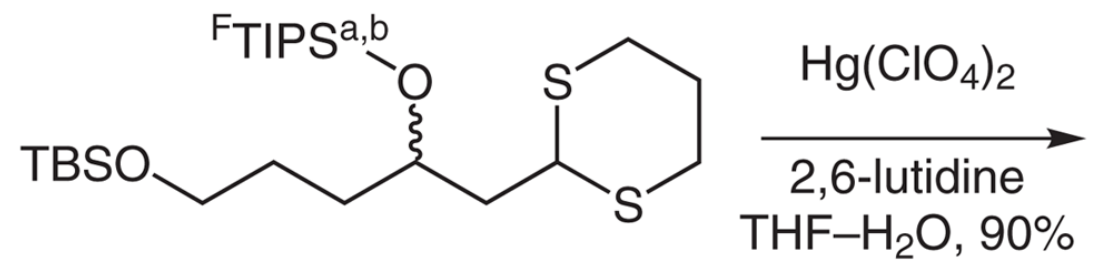

M-9a,b

consists of

$(R)-9 \mathbf{a}$ and $(S)-9 \mathbf{b}$

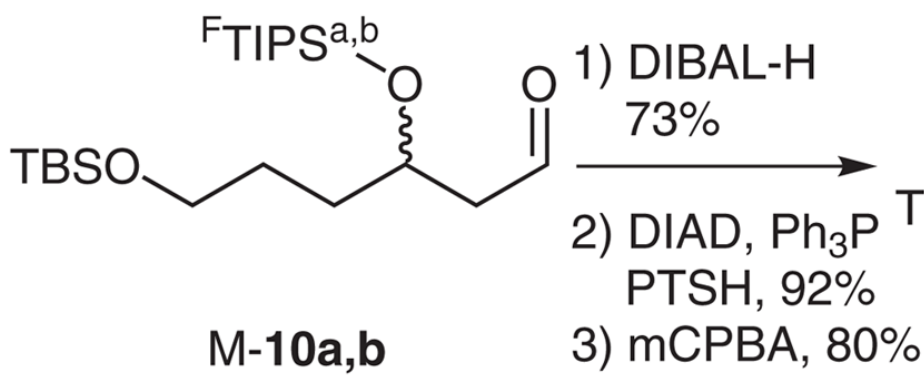

M-3a,b

"a" series tags, $\mathbf{8 a}={ }^{\mathrm{F}}$ TIPSOTf ${ }^{\mathrm{a}}$ where ${ }^{\mathrm{F}}$ TIPS $^{\mathrm{a}}$ is $\mathrm{Si}\left(i-\mathrm{Pr}_{2}\right) \mathrm{CH}_{2} \mathrm{CH}_{2} \mathrm{C}_{4} \mathrm{~F}_{9}$ "b" series tags, $\mathbf{8 b}={ }^{\mathrm{F}}$ TIPSOTf ${ }^{\mathrm{b}}$ where ${ }^{\mathrm{F}}$ TIPS $^{\mathrm{b}}$ is $\mathrm{Si}\left(i-\mathrm{Pr}_{2}\right) \mathrm{CH}_{2} \mathrm{CH}_{2} \mathrm{C}_{3} \mathrm{~F}_{7}$

Scheme 2.

Synthesis of sulfone quasiracemate M-3 


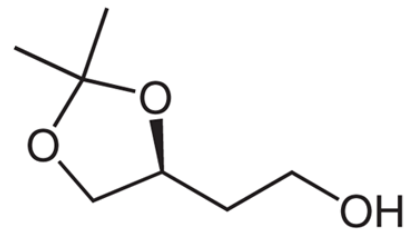

1) $\mathrm{DIAD}, \mathrm{Ph}_{3} \mathrm{P}$ PTSH, $79 \%$

2) $p-\mathrm{TsOH}$, $\mathrm{MeOH}, 93 \%$

3) $\mathrm{TBSCl}$, imidazole, $91 \%$

(S)-11<smiles>O[C@@H](CCSc1nnnn1-c1ccccc1)CO[SbH]</smiles>

(S)-12

1) react $S+8 c, 90 \%$

2) react $R+8 \mathrm{a}, 90 \%$

3) $\mathrm{mix}$<smiles>F[SbH3]O[SbH2]OC[C@H](CCSc1nnnn1-c1ccccc1)O[SbH2]</smiles>

M-13a,c consists of

$(R)-13 \mathrm{a}$ and $(S)-13 \mathrm{c}$

1) $\mathrm{AcCl}, \mathrm{MeOH}, 60 \%$

2) $\mathrm{DMP}, 81 \%$<smiles>CC(C)(C)[SnH](C=O)O[C@@H](C=O)CCSc1nnnn1-c1ccccc1</smiles>

"a" series tags, $\mathbf{8 a}={ }^{\text {FTIPSOTf }}{ }^{\text {a }}$ where ${ }^{\mathrm{F}}$ TIPS ${ }^{\mathrm{a}}$ is $\mathrm{Si}\left(i-\mathrm{Pr}_{2}\right) \mathrm{CH}_{2} \mathrm{CH}_{2} \mathrm{C}_{4} \mathrm{~F}_{9}$ "c" series tags, $\mathbf{8 c}={ }^{\mathrm{F}}$ TIPSOTf $^{\mathrm{C}}$ where ${ }^{\mathrm{F}}$ TIPS $^{\mathrm{c}}$ is $\mathrm{Si}\left(i-\mathrm{Pr}_{2}\right) \mathrm{CH}_{2} \mathrm{CH}_{2} \mathrm{C}_{6} \mathrm{~F}_{13}$

Scheme 3.

Synthesis of aldehyde quasiracemate M-4 


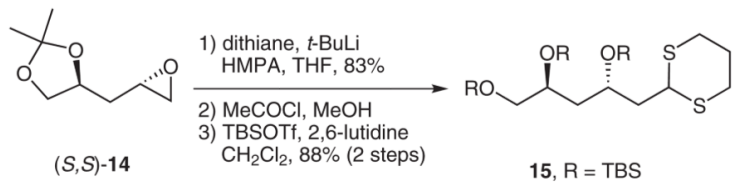

$15+$
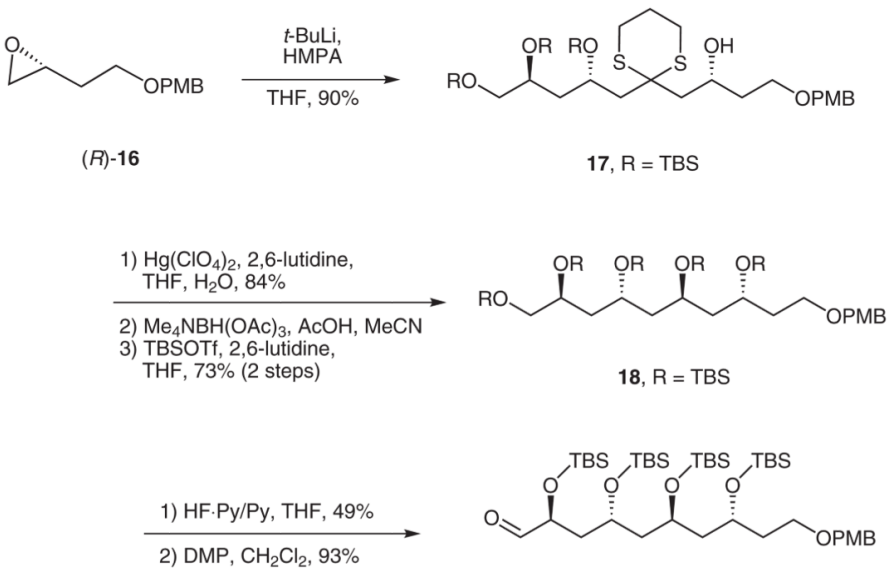

5

Scheme 4.

Synthesis of single isomer fragment 5 

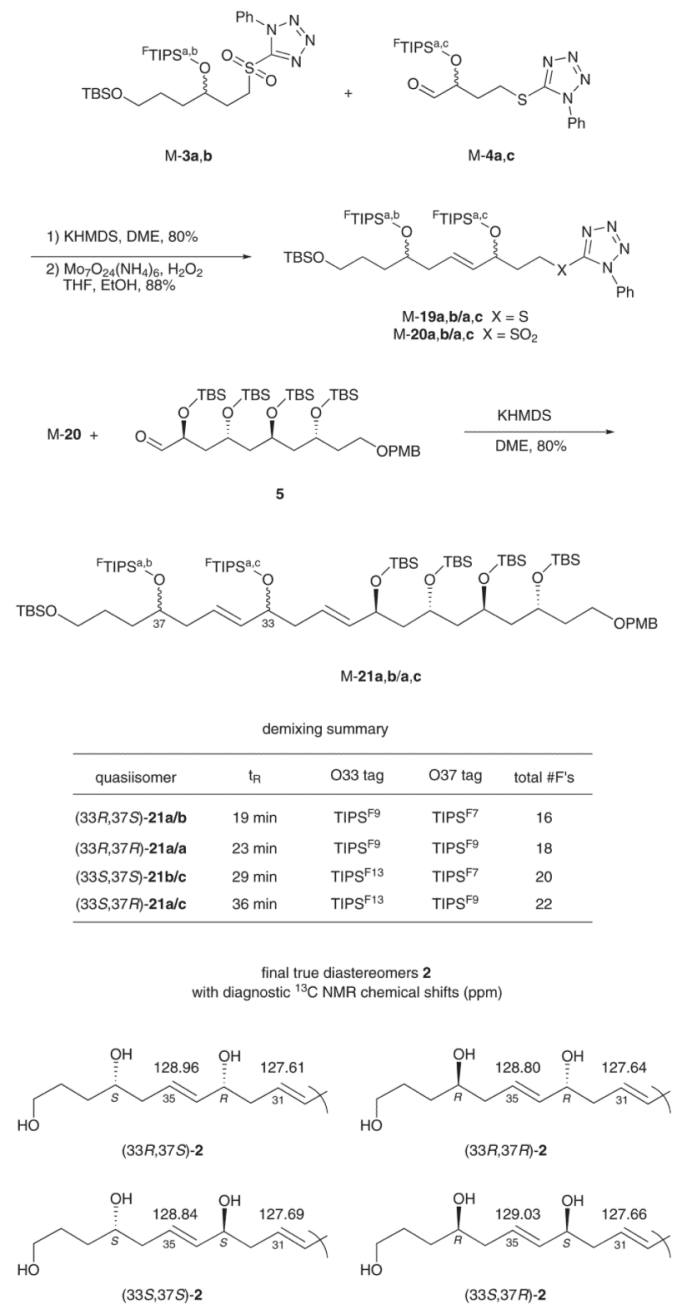

Scheme 5.

Fragment coupling, demixing, and detagging 